\title{
Non-spherical particle mixing behaviors by spherical inert particles assisted in a fluidized bed
}

\author{
An-Xing Ren ${ }^{1,2} \cdot$ Tian-Yu Wang ${ }^{1,2} \cdot$ Tian-Qi Tang ${ }^{1,2} \cdot$ Yu-Rong He ${ }^{1,2}$
}

Received: 26 August 2019 / Published online: 16 November 2019

(c) The Author(s) 2019

\begin{abstract}
Fluidized beds are widely used in many industrial fields such as petroleum, chemical and energy. In actual industrial processes, spherical inert particles are typically added to the fluidized bed to promote fluidization of non-spherical particles. Understanding mixing behaviors of binary mixtures in a fluidized bed has specific significance for the design and optimization of related industrial processes. In this study, the computational fluid dynamic-discrete element method with the consideration of rolling friction was applied to evaluate the mixing behaviors of binary mixtures comprising spherocylindrical particles and spherical particles in a fluidized bed. The simulation results indicate that the differences between rotational particle velocities were higher than those of translational particle velocities for spherical and non-spherical particles when well mixed. Moreover, as the volume fraction of the spherocylindrical particles increases, translational and rotational granular temperatures gradually increase. In addition, the addition of the spherical particles makes the spherocylindrical particles preferably distributed in a vertical orientation.
\end{abstract}

Keywords Non-spherical particle $\cdot$ Fluidized bed $\cdot$ Discrete element method $\cdot$ Binary mixtures

$\begin{array}{ll}\text { Abbreviations } \\ \text { CFD } & \text { Computational fluid dynamic } \\ \text { DEM } & \text { Discrete element method } \\ \text { LSD } & \text { Linear spring dashpot } \\ \text { List of symbols } \\ C_{\mathrm{D}} \quad \text { Drag coefficient } \\ d_{\mathrm{p}} & \text { Particle diameter, } \mathrm{m} \\ \boldsymbol{F}_{\mathrm{c}} & \text { Contact force, } \mathrm{N} \\ \boldsymbol{F}_{\mathrm{d}} & \text { Drag force, } \mathrm{N} \\ \mathbf{g} & \text { Gravitational acceleration, } \mathrm{m} / \mathrm{s}^{2} \\ I_{\mathrm{p}} & \text { Moment of inertia, } \mathrm{kg} \mathrm{m} \mathrm{m}^{2} \\ k & \text { Spring stiffness, } \mathrm{N} / \mathrm{m} \\ m_{\mathrm{p}} & \text { Particle mass, } \mathrm{kg}\end{array}$

Handling Editor: Jun Yao

Edited by Xiu-Qiu Peng

Yu-Rong He

rong@hit.edu.cn

1 School of Energy Science and Engineering, Harbin Institute of Technology, Harbin 150001, China

2 Heilongjiang Key Laboratory of New Energy Storage Materials and Processes, School of Energy Science and Engineering, Harbin Institute of Technology, Harbin 150001, China

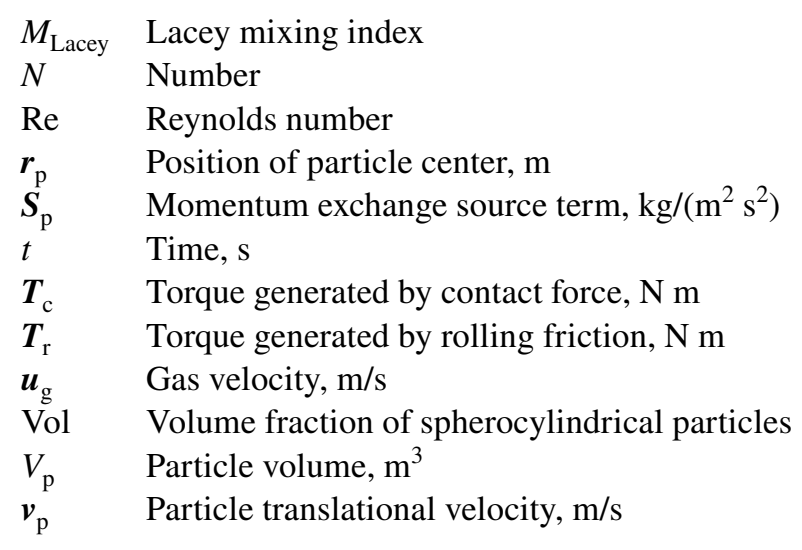

\section{Subscript}

c Contact

g Gas phase

L Local coordinate system

n Normal direction

p Particle phase

rot Rotation

$\mathrm{t}$ Tangential direction

tran Translation

\section{Greek letters}

$\beta \quad$ Interphase momentum exchange coefficient, $\mathrm{kg} /$ $\left(\mathrm{m}^{3} \mathrm{~s}\right)$

$\delta \quad$ Elastic deformation, $\mathrm{m}$ 
$\varepsilon \quad$ Volume fraction

$\theta_{\mathrm{p}, \operatorname{tran}}$ Translational granular temperature, $\mathrm{m}^{2} \mathrm{~s}^{2}$

$\theta_{\mathrm{p}, \mathrm{rot}} \quad$ Rotational granular temperature, $\operatorname{rad}^{2} \mathrm{~s}^{2}$

$\mu \quad$ Friction coefficient

$\mu_{\mathrm{g}} \quad$ Gas shear viscosity, Pa s

$\rho \quad$ Density, $\mathrm{kg} / \mathrm{m}^{3}$

$\tau \quad$ Stress tensor

$\omega \quad$ Rotational velocity, $\mathrm{rad} / \mathrm{s}$

$\chi \quad$ Voidage function exponent

$\sigma \quad$ Variance

$\Phi \quad$ Sphericity

$\Phi_{\perp} \quad$ Crosswise sphericity

$\Phi_{\|} \quad$ Lengthwise sphericity

\section{Introduction}

Fluidized beds are widely used in many industrial fields such as petroleum, chemical and energy due to their uniform mixing, large contact surfaces between phases and efficient heat transfer and mass transfer (Van Der Hoef et al. 2006). Many studies and applications have shown that circulating fluidized beds have become an important reactor for the combustion and utilization of petroleum coke (Chen and Lu 2007). The process of biomass conversion and utilization is also often carried out in a fluidized bed (Cui and Grace 2007). However, fluidization of biomass particles is a difficult task because the non-spherical biomass particles are generally large and have a low density. In the actual industrial processes, inert particles such as silica sand, alumina and calcite are often added to the biomass to assist its fluidization (Fotovat et al. 2013). Therefore, understanding mixing behaviors of binary mixtures in a fluidized bed has specific significance for the design and optimization of related industrial processes.

In recent years, many researchers have conducted experimental studies on the macroscopic flow and mixing behaviors of granular systems containing non-spherical particles. Zhang et al. (2009) experimentally studied the mixing and separation behaviors of biomass-sand binary mixture in a fluidized bed and analyzed the variation of flow pattern and mixing index. Fotovat et al. (2014) investigated effects of superficial gas velocity and the mixture composition on the mixing/segregation characteristics by analyzing the circulatory motion of the active tracer. Shao et al. (2016) investigated the mixing behaviors in binary-component and multicomponent particulate systems and found that the density of non-spherical particles has a more significant influence on the mixing characteristics than particle size and shape. Boer et al. (2018) developed a digital image analysis technique to explore the particle distributions in the fluidized bed and obtained qualitative and quantitative experimental results which can be used for validation of numerical models concerning non-spherical particle mixing. In general, it is difficult to obtain microscopic flow characteristics through experimental methods, and numerical simulation can obtain more detailed information, which is a good complement to the experiment. Among the many simulation methods, the computational fluid dynamics-discrete element method (CFD-DEM) has attracted much attention due to the fact that the motion characteristics of each particle can be obtained. Tsuji et al. (1993) coupled DEM proposed by Cundall and Strack (1979) with CFD to describe the gas-solid two-phase flow in fluidized beds. Currently, CFD-DEM has been widely used to evaluate the flow characteristics of spherical particles in bubbling fluidized beds (Müller et al. 2008; Luo et al. 2014; Wang et al. 2015; Wang et al. 2016a, b; Liu and van Wachem 2019), spouted beds (Takeuchi et al. 2004; He et al. 2016) and spouted fluidized beds (Luo et al. 2015; Van Buijtenen et al. 2011; Tang et al. 2017; Wang et al. 2016c).

In previous studies, the assumption of spherical particles was common. However, in the actual industrial process, particles are mostly non-spherical particles, and particle shape has a great influence on the macroscopic flow characteristics (Hilton et al. 2010). Recently, some scholars have applied CFD-DEM to study non-spherical particle flow behaviors in a fluidized bed. Hilton et al. (2010) studied the flow characteristics of spherical particles, cubes and ellipsoidal particles in a fluidized bed and found that the non-spherical particles have larger drag force at the same superficial gas velocity, leading to earlier fluidization. Zhou et al. (2011) evaluated the flow characteristics of ellipsoidal particles and analyzed the effect of aspect ratio on particle orientation and force structure. Cai et al. (2012) investigated the orientation distribution of cylindrical particles in the riser and found that the orientation of cylindrical particles is affected by their position more than the shape and local gas velocity.

In the process of fluidization and utilization of biomass, mixtures comprising non-spherical particles are often involved. Therefore, it is necessary not only to study the flow characteristics of the monocomponent non-spherical particle system, but also to further investigate the mixing characteristics of the multi-component non-spherical particle system. Ren et al. (2013) investigated the mixing behavior of binary mixtures comprising corn-shaped particles and spheres in a spouted bed and pointed out that particles with closer sizes could be better mixed. Vollmari et al. (2015) evaluated the mixing behavior bidisperse mixtures of various shaped particles and found that the mixing was strongly influenced by the shape of the particles and the addition of plates can accelerate the mixing. Ma and Zhao (2018) investigated the fluidization of binary mixtures comprising spheres and 
rod-like particles and analyzed the effect of volume fraction of the rod-like particles on the minimum fluidization velocity and particle orientation.

Currently, there are few simulation studies on the mixing characteristics of binary mixtures containing non-spherical particles in a fluidized bed, and the understanding of microscopic characteristics such as granular temperature and particle orientation in the bed is not sufficient. Therefore, it is necessary to further investigate the mixing behavior and microscopic characteristics of binary mixtures containing nonspherical particles in a fluidized bed. In this study, CFD-DEM simulations with rolling resistance were carried out to evaluate the mixing behaviors of binary mixtures comprising spherocylindrical particles and spherical particles in a fluidized bed. The macroscale mixing behaviors and microscale hydrodynamic characteristics including granular temperature and particle orientation were discussed.

\section{Model description}

\subsection{Gas phase}

The gas phase is considered to be a continuous phase and modeled by the volume-averaged Navier-Stokes equations as shown below:

$\frac{\partial\left(\varepsilon_{\mathrm{g}} \rho_{\mathrm{g}}\right)}{\partial t}+\nabla \cdot\left(\varepsilon_{\mathrm{g}} \rho_{\mathrm{g}} \boldsymbol{u}_{\mathrm{g}}\right)=0$

$\frac{\partial\left(\varepsilon_{\mathrm{g}} \rho_{\mathrm{g}} \boldsymbol{u}_{\mathrm{g}}\right)}{\partial t}+\nabla \cdot\left(\varepsilon_{\mathrm{g}} \rho_{\mathrm{g}} \boldsymbol{u}_{\mathrm{g}} \boldsymbol{u}_{\mathrm{g}}\right)=-\varepsilon_{\mathrm{g}} \nabla P-\boldsymbol{S}_{\mathrm{p}}-\nabla \cdot\left(\varepsilon_{\mathrm{g}} \boldsymbol{\tau}_{\mathrm{g}}\right)+\varepsilon_{\mathrm{g}} \rho_{\mathrm{g}} \mathbf{g}$ where $\varepsilon_{\mathrm{g}}$ is the porosity; $t$ is the time, $\mathrm{s} ; \boldsymbol{u}_{\mathrm{g}}$ is the velocity of gas phase, $\mathrm{m} / \mathrm{s} ; \rho_{\mathrm{g}}$ is the density of gas phase, $\mathrm{kg} / \mathrm{m}^{3} ; \boldsymbol{S}_{\mathrm{p}}$ is the momentum exchange source term, $\mathrm{kg} /\left(\mathrm{m}^{2} \mathrm{~s}^{2}\right) ; \tau_{\mathrm{g}}$ is the viscous stress tensor, $\mathrm{kg} /\left(\mathrm{m} \mathrm{s}^{2}\right)$.

$\boldsymbol{S}_{\mathrm{p}}=-\frac{1}{V_{\mathrm{c}}} \sum_{i}^{N_{\mathrm{c}}} \boldsymbol{F}_{\mathrm{d} i}$

$\boldsymbol{\tau}_{\mathrm{g}}=\frac{2}{3} \mu_{\mathrm{g}}\left(\nabla \cdot \boldsymbol{u}_{\mathrm{g}}\right) \boldsymbol{I}-\mu_{\mathrm{g}}\left[\left(\nabla \boldsymbol{u}_{\mathrm{g}}\right)+\left(\nabla \boldsymbol{u}_{\mathrm{g}}\right)^{\mathrm{T}}\right]$

where $V_{\mathrm{c}}$ is the characteristic fluid volume, $\mathrm{m}^{3} ; N_{\mathrm{c}}$ is the number of particles in the characteristic fluid volume; $\boldsymbol{F}_{\mathrm{d}}$ is the drag force, $\mathrm{N} ; \mu_{\mathrm{g}}$ is the gas shear viscosity, $\mathrm{Pa} \mathrm{s} ; \boldsymbol{I}$ is the unit tensor.

\subsection{Solid phase}

The solid phase is treated to be a discrete phase, and the motion of each individual particle is directly solved by Newton's second law. The translational motion equation of a nonspherical particle is given as follows:

$m_{\mathrm{p}} \frac{\mathrm{d}^{2} \boldsymbol{r}}{\mathrm{d} t^{2}}=-V_{\mathrm{p}} \nabla P+m_{\mathrm{p}} \mathbf{g}+\boldsymbol{F}_{\mathrm{c}}+\boldsymbol{F}_{\mathrm{d}}$

where $m_{\mathrm{p}}$ is the mass of particle, $\mathrm{kg} ; \boldsymbol{r}$ is the position of particle center, $\mathrm{m} ; \boldsymbol{v}_{\mathrm{p}}$ is the translational velocity of particle, $\mathrm{m} / \mathrm{s} ; \boldsymbol{F}_{\mathrm{c}}$ is the contact force, $\mathrm{N}$.

In this study, each non-spherical particle is modeled by the multi-sphere method (Favier et al. 1999). In the multisphere method, the contact force and torque acting on a nonspherical particle are obtained by calculating the sum of

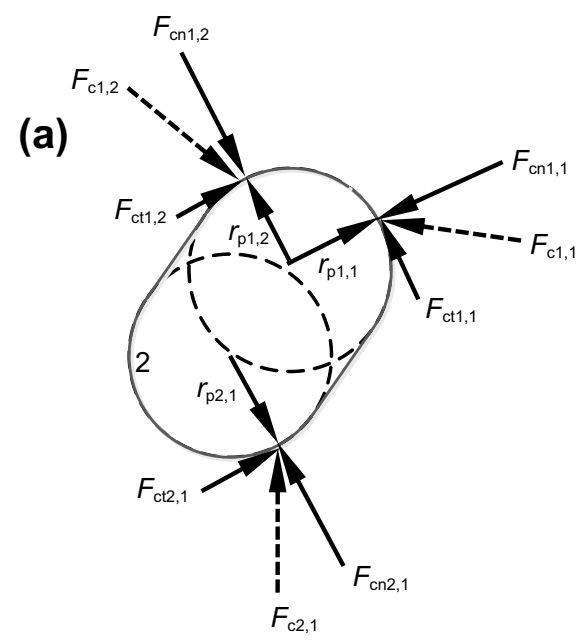

(b)

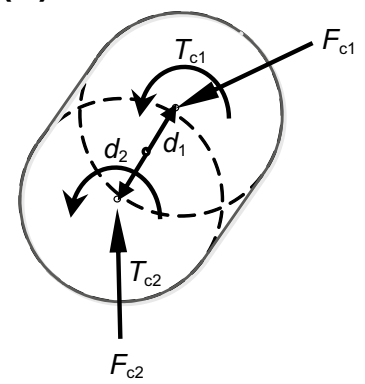

(c)

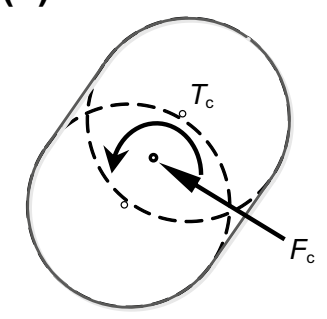

Fig. 1 Schematic diagram of transferring the force acting on the elemental sphere to the centroid of a non-spherical particle. a Forces, respectively, acting on each element sphere; $\mathbf{b}$ forces and torques acting on the center of each element sphere; $\mathbf{c}$ forces and torques acting on the center of a non-spherical particle 
contact forces and torques on its spherical elements. Figure 1 shows the schematic diagram of transferring the force acting on the elemental sphere to the centroid of a non-spherical particle. To reduce the computational cost, a two-step method (Wang et al. 2016b) was used for contact detection.

The contact force acting on spherical element was calculated using a linear spring-dashpot (LSD) model and consists of a normal component $\boldsymbol{F}_{\mathrm{n}}$ and a tangential component $\boldsymbol{F}_{\mathrm{t}}$ :

$F_{\mathrm{n}}=-k_{\mathrm{n}} \delta_{\mathrm{n}}-\eta_{\mathrm{n}} \boldsymbol{v}_{\mathrm{n}}$

$\boldsymbol{F}_{\mathrm{t}}= \begin{cases}-k_{\mathrm{t}} \boldsymbol{\delta}_{\mathrm{t}}-\eta_{\mathrm{t}} \boldsymbol{v}_{\mathrm{t}} & \left|\boldsymbol{F}_{\mathrm{t}}\right| \leq \mu_{\mathrm{f}}\left|\boldsymbol{F}_{\mathrm{n}}\right| \\ -\mu_{\mathrm{f}}\left|\boldsymbol{F}_{\mathrm{n}}\right| \boldsymbol{v}_{\mathrm{t}}\left|\boldsymbol{v}_{\mathrm{t}}\right| & \left|\boldsymbol{F}_{\mathrm{t}}\right|>\mu_{\mathrm{f}}\left|\boldsymbol{F}_{\mathrm{n}}\right|\end{cases}$

where $k$ is the spring stiffness $(\mathrm{N} / \mathrm{m}) ; \delta$ is the elastic deformation (m); $\eta$ is the damping coefficient $(\mathrm{N} \mathrm{s} / \mathrm{m}) ; \boldsymbol{v}$ is the relative velocity $(\mathrm{m} / \mathrm{s}) ; \mu_{\mathrm{f}}$ is the sliding friction coefficient. The subscripts $\mathrm{n}$ and $\mathrm{t}$ indicate the variables in normal direction and tangential direction, respectively.

Since the non-spherical particles inertia moment changes constantly during the rotation, the rotational motion of the non-spherical particles is more complicated than that of the spherical particles. To describe the rotational motion of non-spherical particles more conveniently, two coordinate systems are generally introduced: (a) a global coordinate system and (b) a local coordinate system. The angular momentum equation is solved in a local coordinate system, and the rotational variables are transformed between the local coordinate system and global coordinate system using the quaternion method (Wachem et al. 2015). As shown in

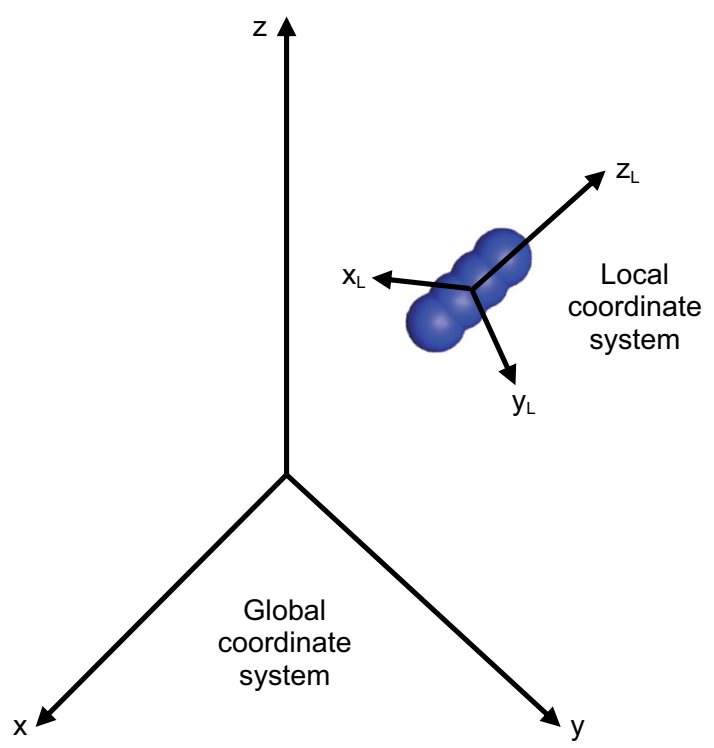

Fig. 2 Schematic diagram of the local coordinate system
Fig. 2, the direction of the coordinate axis of the local coordinate system is the direction of the principal axis of the particle's inertia.

$\boldsymbol{I}_{\mathrm{L}} \frac{\mathrm{d} \boldsymbol{\omega}_{\mathrm{L}}}{\mathrm{d} t}+\boldsymbol{\omega}_{\mathrm{L}} \times\left(\boldsymbol{I}_{\mathrm{L}} \cdot \boldsymbol{\omega}_{\mathrm{L}}\right)=\boldsymbol{T}_{\mathrm{L}}=\boldsymbol{T}_{\mathrm{c}}+\boldsymbol{T}_{\mathrm{r}}$

where $\boldsymbol{I}_{\mathrm{L}}$ is the inertia tensor $\left(\mathrm{kg} \mathrm{m}^{2}\right) ; \boldsymbol{\omega}_{\mathrm{L}}$ is the rotational velocity of particle in a local coordinate system $(\mathrm{rad} / \mathrm{s}) ; \boldsymbol{T}_{\mathrm{L}}$ is the torque in a local coordinate system $(\mathrm{N} \mathrm{m}) ; \boldsymbol{T}_{\mathrm{c}}$ is the torque generated by contact force $(\mathrm{N} \mathrm{m}) ; \boldsymbol{T}_{\mathrm{r}}$ is the torque generated by rolling friction $(\mathrm{N} \mathrm{m})$.

The torque generated by rolling friction is attributed to the elastic hysteresis loss or viscous dissipation and slows down the relative rotations of particles (Zhou et al. 1999). Goniva et al. (2012) found that rolling friction can affect the velocity of spherical particles in spouted fluidized beds and simulation results can be improved significantly when applying a rolling friction model. In this study, the correlation proposed by Brilliantov and Pöschel (1998) was used to calculate the torque on contacting spherical elements generated by rolling friction as follows:

$\boldsymbol{T}_{\mathrm{ri}}=-\mu r_{\mathrm{p}}\left|\boldsymbol{F}_{\mathrm{n}}\right| \hat{\boldsymbol{\omega}}_{i}$

where $\mu$ is the rolling friction coefficient; $r_{\mathrm{p}}$ is the radius of spherical element (m); $\left|\boldsymbol{F}_{\mathrm{n}}\right|$ is the magnitude of normal contact force $(\mathrm{N}) ; \boldsymbol{\omega}$ is the rotational velocity of particle $(\mathrm{rad} / \mathrm{s})$.

\subsection{Interphase exchange}

Based on the drag force applied on a spherical particle, Di Felice (1994) proposed a drag correlation in multi-particle systems by experimental fitting.

$\boldsymbol{F}_{\mathrm{d}}=\frac{1}{2} \rho_{\mathrm{g}} C_{\mathrm{D}} A_{\perp}\left|\boldsymbol{u}_{\mathrm{g}}-\boldsymbol{v}_{\mathrm{p}}\right|\left(\boldsymbol{u}_{\mathrm{g}}-\boldsymbol{v}_{\mathrm{p}}\right) \varepsilon_{\mathrm{g}}^{2-\chi}$

$\chi=3.7-0.65 \exp \left[-\frac{\left(1.5-\log _{10} \operatorname{Re}\right)^{2}}{2}\right]$

Based on the experimental data obtained from Leith (1987), Ganser (1993), Tran-Cong et al. (2004) and a comprehensive numerical study, Hölzer and Sommerfeld (2008) established a simple and accurate drag model for non-spherical particles:

$C_{\mathrm{D}}=\frac{8}{\operatorname{Re}} \frac{1}{\sqrt{\Phi_{\|}}}+\frac{16}{\operatorname{Re}} \frac{1}{\sqrt{\Phi}}+\frac{3}{\sqrt{\operatorname{Re}}} \frac{1}{\Phi^{\frac{3}{4}}}+0.42 \times 10^{0.4(-\log \Phi)^{0.2}} \frac{1}{\Phi_{\perp}}$

where $\Phi$ is the sphericity, $\Phi_{\perp}$ is the crosswise sphericity, and $\Phi_{\|}$is the lengthwise sphericity. Re is defined as follows, 
$\operatorname{Re}=\frac{\varepsilon_{\mathrm{g}} d_{\mathrm{p}}\left|\boldsymbol{u}_{\mathrm{g}}-\boldsymbol{v}_{\mathrm{p}}\right| \rho_{\mathrm{g}}}{\mu_{\mathrm{g}}}$

In this study, Di Felice (1994) correlation and Hölzer and Sommerfeld (2008) drag model were used to describe interphase momentum exchange. This method has been used in many studies in non-spherical granular systems (Hilton et al. 2010; Gan et al. 2017; Ma et al. 2017).

\subsection{Particle granular temperature}

The particle granular temperature is the turbulent energy of particles, indicating the velocity fluctuations of particles (Tartan and Gidaspow 2004; Jung et al. 2005). The particle translational granular temperature is defined as the mean of second moment of particle translational velocity fluctuation:

$\left\langle C_{i} C_{j}\right\rangle=\frac{1}{n} \sum_{k=1}^{n}\left[v_{\mathrm{p}, i k}(x, t)-c_{i}(x, t)\right]\left[v_{\mathrm{p}, j k}(x, t)-c_{j}(x, t)\right]$

where $i, j$ represent $x, y$ or $z$ directions, $n$ is the number of particles in a unit volume, and $v_{\mathrm{p}}(x, t)$ is the instantaneous translational velocity of particles. The average translational velocity $c_{i}(x, t)$ can be expressed as follows:

$c_{i}(x, t)=\frac{1}{n} \sum_{k=1}^{n} v_{\mathrm{p}, i k}(x, t)$

Similarly, the particle rotational granular temperature $\left(\theta_{\mathrm{p}, \mathrm{rot}}(x, t)\right)$ can be obtained as follows:

$\left\langle C_{\mathrm{rot}, i} C_{\mathrm{rot}, j}\right\rangle=\frac{1}{n} \sum_{k=1}^{n}\left[\omega_{\mathrm{p}, i k}(x, t)-c_{\mathrm{rot}, i}(x, t)\right]\left[\omega_{\mathrm{p}, j k}(x, t)-c_{\mathrm{rot}, j}(x, t)\right]$

where $\omega_{\mathrm{p}}(x, t)$ is the instantaneous rotational velocity of particles. The average rotational velocity $c_{\text {rot }, i}(x, t)$ can be expressed as follows:

$c_{\mathrm{rot}, i}(x, t)=\frac{1}{n} \sum_{k=1}^{n} \omega_{\mathrm{p}, i k}(x, t)$.

\subsection{Initial and boundary conditions}

As shown in Fig. 3, the dimension of the fluidized bed in the simulation was $150 \mathrm{~mm}, 20 \mathrm{~mm}$ and $400 \mathrm{~mm}$ in width, depth and height, respectively. At the bottom of fluidized bed, uniform airflow was injected through the air distribution plate. A pressure outlet boundary condition was used
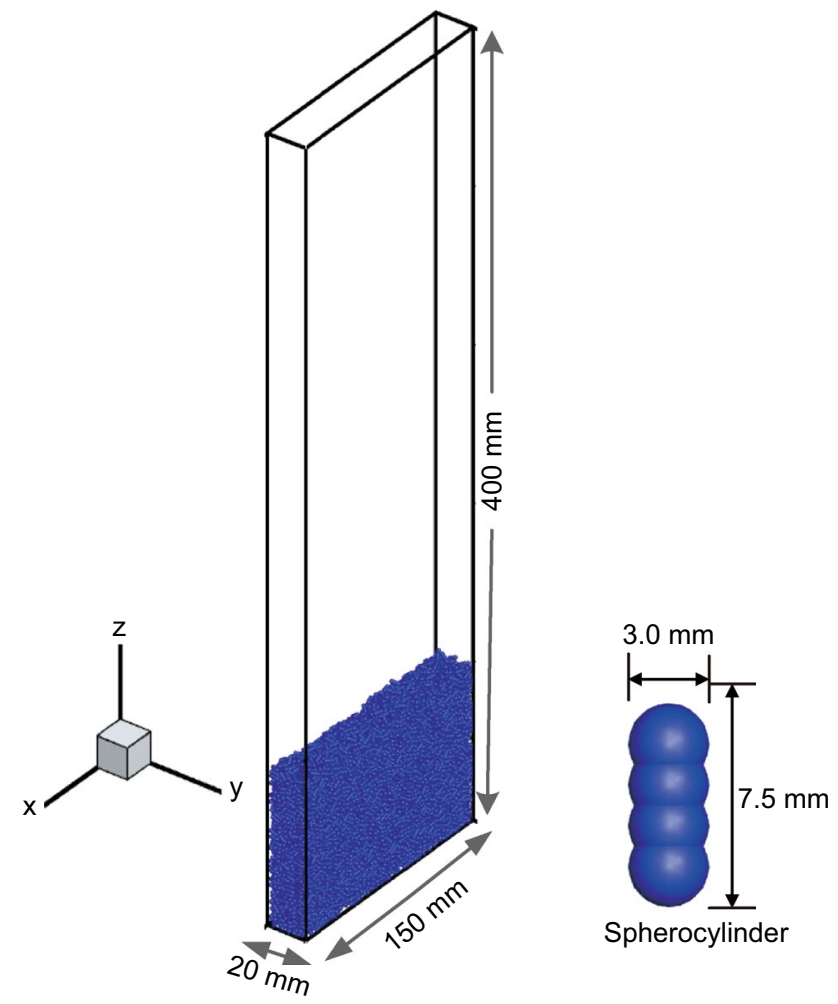

Fig. 3 Schematic geometry of the fluidized bed and the spherocylindrical particle

Table 1 Parameters applied in the simulation

\begin{tabular}{lll}
\hline Variable & Value & Unit \\
\hline Bed & & \\
Dimensions in $x, y$ and $z$ directions & $150 \times 20 \times 400$ & $\mathrm{~mm}$ \\
Grids in $x, y$ and $z$ directions & $15 \times 2 \times 40$ & - \\
$\begin{array}{l}\text { Particles } \\
\text { Density, } \rho_{\mathrm{p}}\end{array}$ & 1050 & $\mathrm{~kg} / \mathrm{m}^{3}$ \\
Coefficient of restitution, $e$ & 0.5 & - \\
Coefficient of sliding friction between & 0.4 & - \\
$\quad$ particles, $\mu_{\mathrm{f} \_p p}$ & & \\
Coefficient of rolling friction, $\mu$ & 0.1 & - \\
Coefficient of sliding friction between & 0.3 & - \\
$\quad$ particle and wall, $\mu_{\mathrm{f} \_p w}$ & & $\mathrm{~N} / \mathrm{m}$ \\
Normal spring stiffness, $k_{\mathrm{n}}$ & 10,000 & $\mathrm{~N} / \mathrm{m}$ \\
Tangential spring stiffness, $k_{\mathrm{t}}$ & 3063.8 & \\
Gas & & $\mathrm{m} / \mathrm{s}$ \\
Superficial gas velocity, $U_{\mathrm{g}}$ & $1.6 / 2.0$ & $\mathrm{~kg} / \mathrm{m}^{3}$ \\
Density, $\rho_{\mathrm{g}}$ & 1.2 & $\mathrm{~Pa} \mathrm{~s}$ \\
Viscosity, $\mu_{\mathrm{g}}$ & $1.8 \times 10^{-5}$ & $\mathrm{~Pa}$ \\
Outlet pressure, $P$ & 101,325 & \\
\hline
\end{tabular}


at the top of the bed, and a no-slip boundary condition was applied at the walls for the gas phase. The spring stiffness and damping coefficient significantly affect the maximum overlap of particle collisions. Kruggel-Emden et al. (2010) suggested a maximum overlap of $1 \%$ of the particle diameter to avoid alteration of the simulations. The spring stiffness was chosen so that the maximum overlap condition is fulfilled. The parameters applied in the simulation are summarized in Table 1.

The particles in the simulation included spherical particles ( $3 \mathrm{~mm}$ in diameter) and spherocylindrical particles modeled by a multi-sphere method $(7.5 \mathrm{~mm}$ in long diameter, $3 \mathrm{~mm}$ in short diameter, as shown in Fig. 3). The volume fraction of the spherocylinders ( $\mathrm{Vol})$ in the binary mixtures

Table 2 Composition of the granular systems in the simulation

\begin{tabular}{llc}
\hline $\begin{array}{l}\text { The volume fraction of the } \\
\text { spherocylinders (Vol), } \%\end{array}$ & $\begin{array}{l}\text { Number of the } \\
\text { spherocylinders }\end{array}$ & $\begin{array}{l}\text { Number of } \\
\text { the spheres }\end{array}$ \\
\hline 100 & 4000 & 0 \\
75 & 3000 & 3240 \\
50 & 2000 & 6480 \\
25 & 1000 & 9720 \\
\hline
\end{tabular}

in the fluidized bed was $100 \%, 75 \%, 50 \%$ and $25 \%$, respectively. Composition of the granular systems in the simulation is summarized in Table 2. As shown in Fig. 4, at the initial moment $(t=0 \mathrm{~s})$, the spherocylinders marked in blue are stacked above the spherical particles marked in red. In this study, the CFD time step is $5 \times 10^{-5} \mathrm{~s}$ and the DEM time step is $5 \times 10^{-6} \mathrm{~s}$.

\section{Results and discussion}

\subsection{Mixing behaviors}

Figure 5 shows the instantaneous particle distribution at $t=10 \mathrm{~s}$ at $U_{\mathrm{g}}=1.6 \mathrm{~m} / \mathrm{s}$ and $U_{\mathrm{g}}=2.0 \mathrm{~m} / \mathrm{s}$. It can be seen that under two superficial gas velocities, the spherocylindrical particles and the spherical particles are uniformly mixed at $t=10 \mathrm{~s}$. In addition, due to the presence of the spherocylindrical particles, the large bubbles are not always in the middle of the bed and may appear in the vicinity of the left and right walls. It can also be observed that the bed expansion height is higher with superficial gas velocity of $2.0 \mathrm{~m} / \mathrm{s}$.

The averaged translational velocities of the spherocylindrical particles and spherical particles during $0-10 \mathrm{~s}$ are

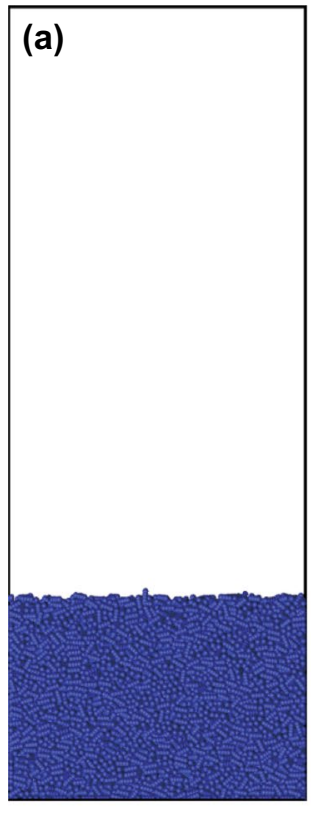

$\mathrm{Vol}=100 \%$

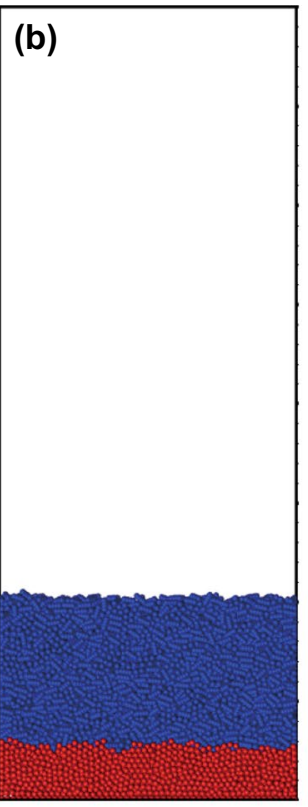

$\mathrm{Vol}=75 \%$

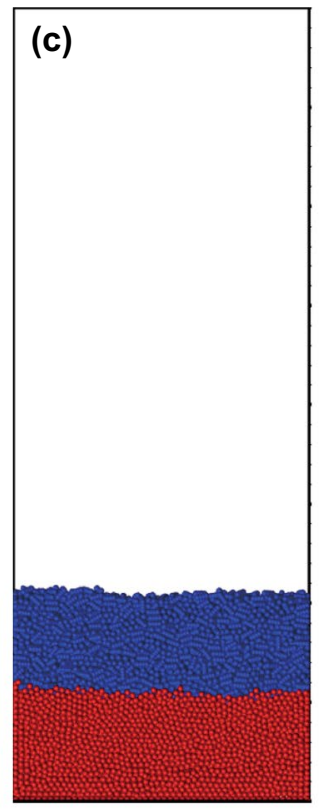

$\mathrm{Vol}=50 \%$

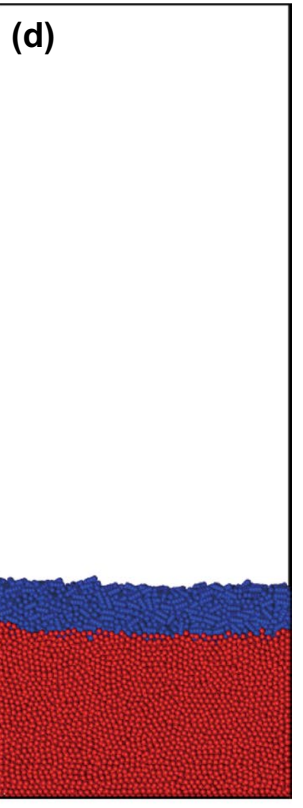

$\mathrm{Vol}=25 \%$

Fig. 4 Initial particle distribution in the fluidized bed (spherocylindrical particles marked in blue; spherical particles marked in red). a $\mathrm{Vol}=100 \%, \mathbf{b ~ V o l}=75 \%, \mathbf{c ~ V o l}=50 \%, \mathbf{d ~ V o l}=25 \%$ 


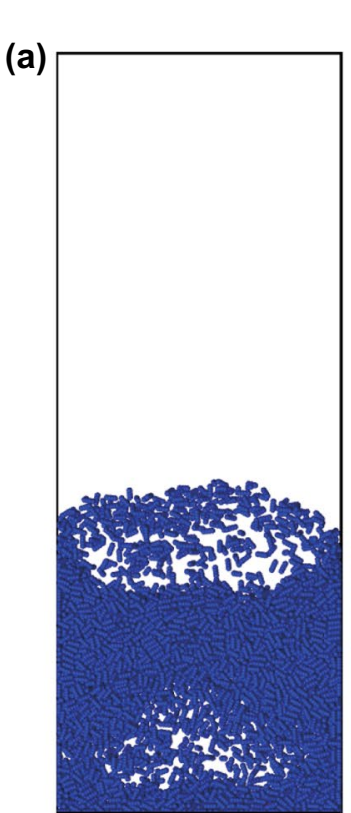

$\mathrm{Vol}=100 \%$

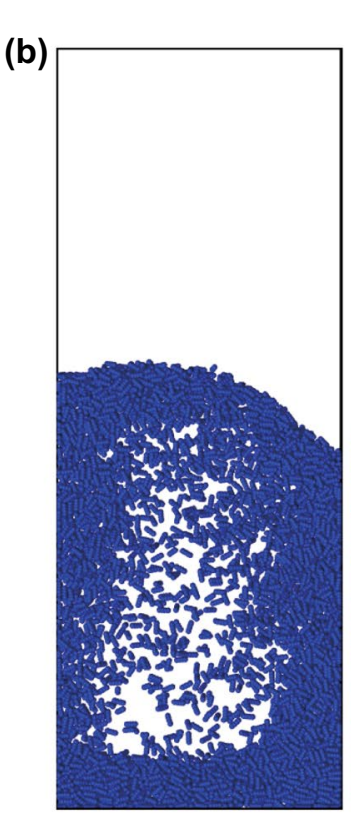

$\mathrm{Vol}=100 \%$

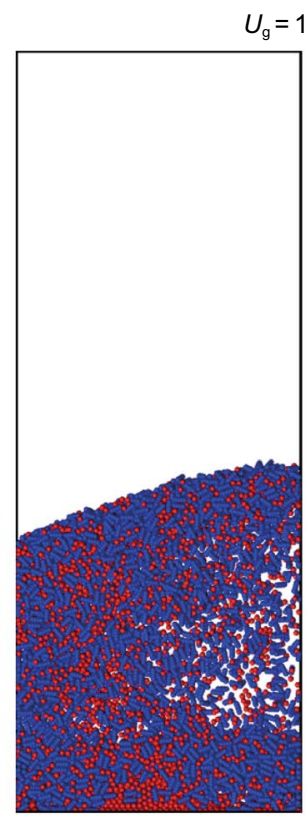

$\mathrm{Vol}=75 \%$

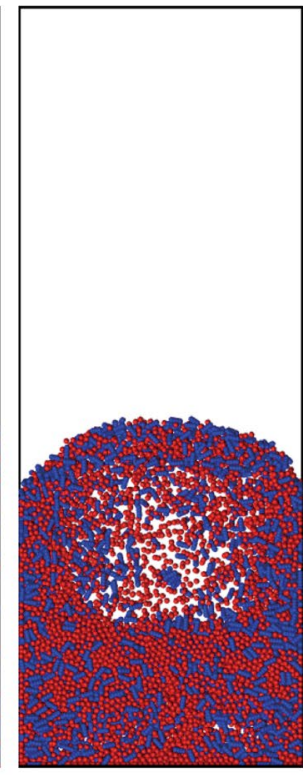

$\mathrm{Vol}=50 \%$

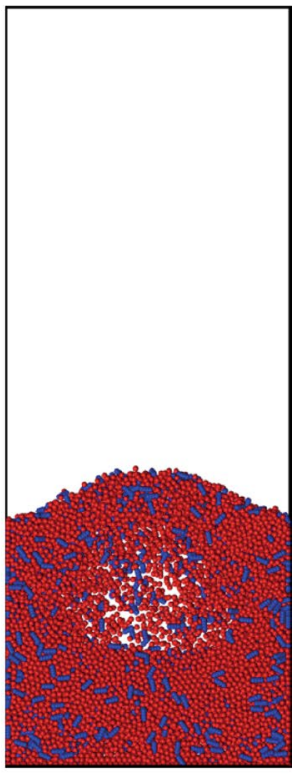

$\mathrm{Vol}=25 \%$

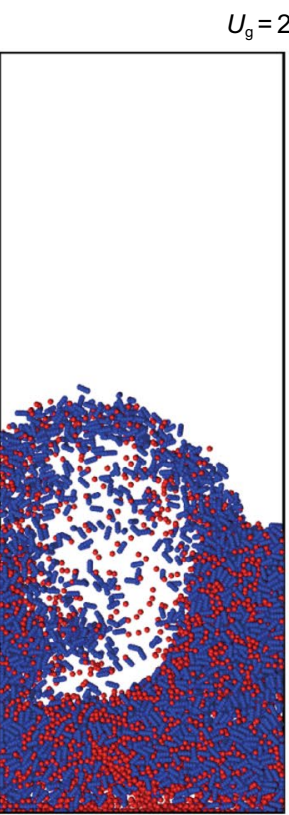

$\mathrm{Vol}=75 \%$

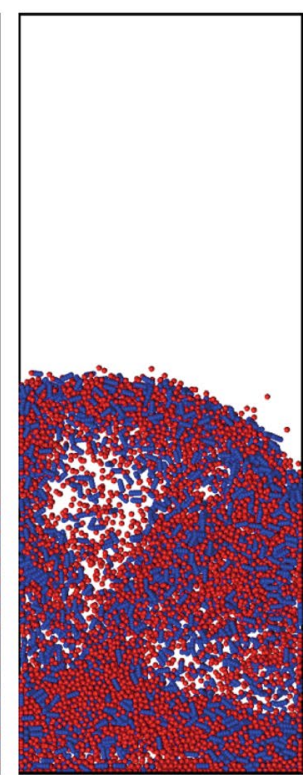

$\mathrm{Vol}=50 \%$

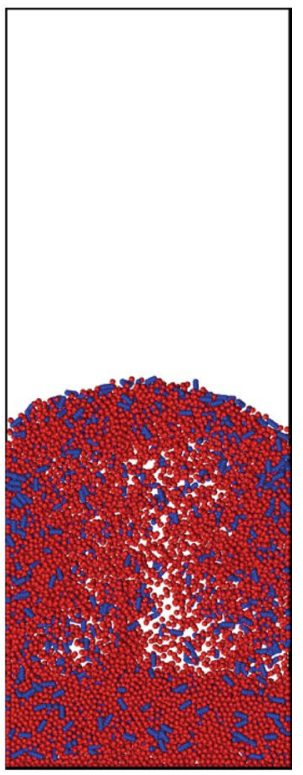

$\mathrm{Vol}=25 \%$

Fig. 5 Snapshots of particle distribution at $t=10 \mathrm{~s}$ at $U_{\mathrm{g}}=1.6 \mathrm{~m} / \mathrm{s}$ and $U_{\mathrm{g}}=2.0 \mathrm{~m} / \mathrm{s}, \mathbf{a} U_{\mathrm{g}}=1.6 \mathrm{~m} / \mathrm{s}(\mathrm{Vol}=100 \%, \mathrm{Vol}=75 \%, \mathrm{Vol}=50 \%$, $\mathrm{Vol}=25 \%)$, b $U_{\mathrm{g}}=2.0 \mathrm{~m} / \mathrm{s}(\mathrm{Vol}=100 \%, \mathrm{Vol}=75 \%, \mathrm{Vol}=50 \%$, $\mathrm{Vol}=25 \%)$

shown in Fig. 6. The average particle translational velocities are calculated as follows:

$\left|v_{\mathrm{p}}\right|=\frac{1}{N} \sum_{i=1}^{N} \sqrt{v_{\mathrm{p} x}^{2}+v_{\mathrm{p} y}^{2}+v_{\mathrm{p} z}^{2}}$
It can be found that the instantaneous average translational velocities of the spherocylindrical particles at the initial stage are greater than that of the spherical particles, but after a few seconds, the average translational velocities 

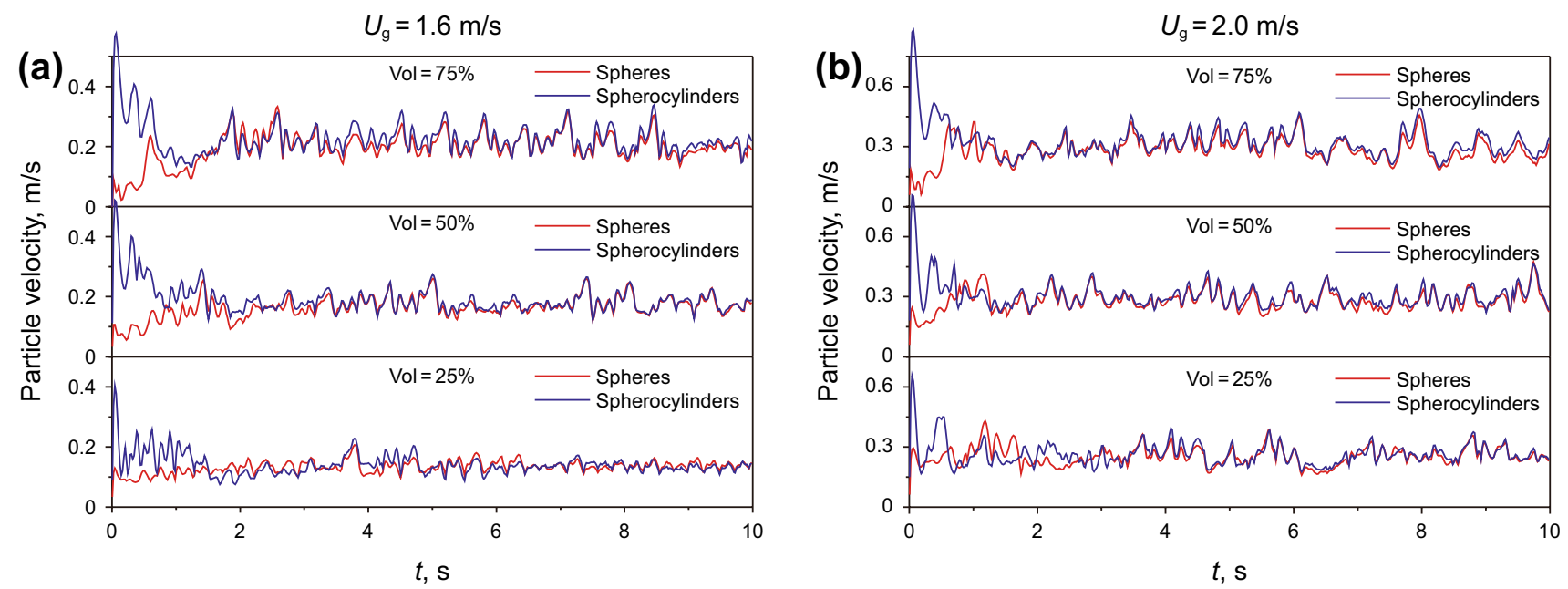

Fig. 6 The average translational velocities of the spherocylindrical particles and spherical particles during $0-10 \mathrm{~s}$ at $\mathbf{a} U_{\mathrm{g}}=1.6 \mathrm{~m} / \mathrm{s}$ and $\mathbf{b}$ $U_{\mathrm{g}}=2.0 \mathrm{~m} / \mathrm{s}$
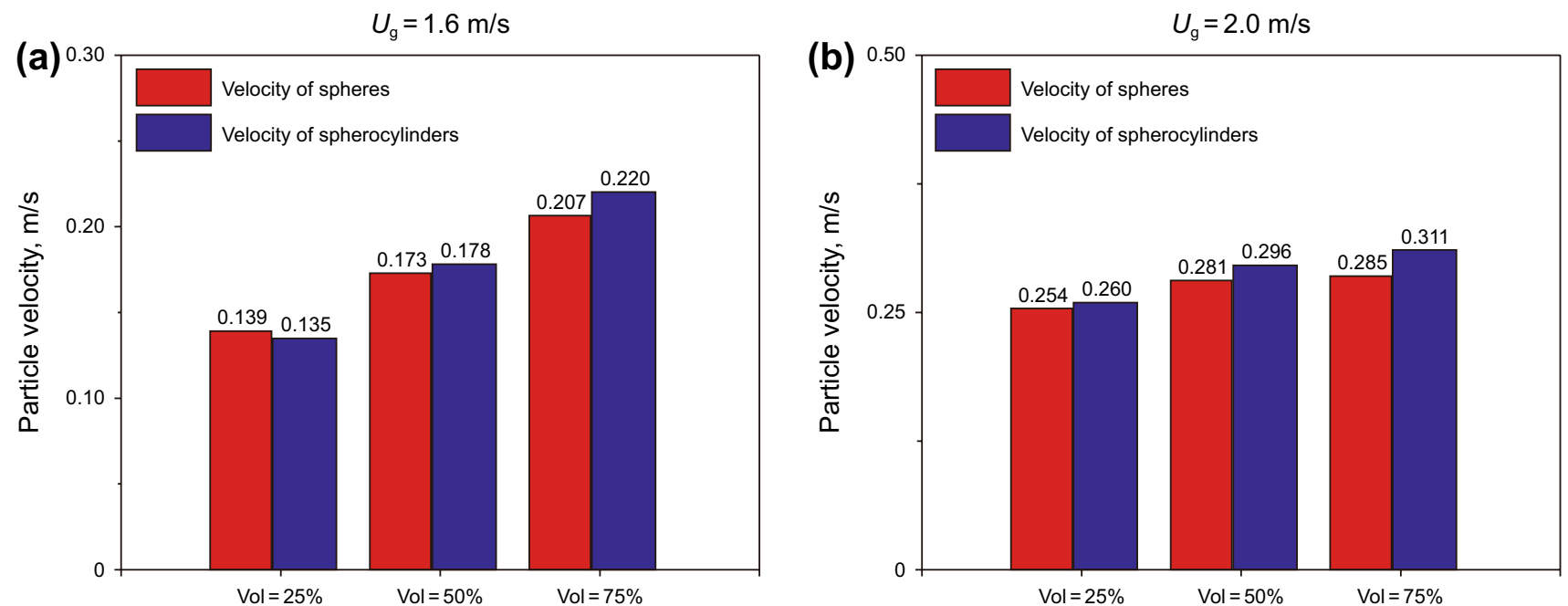

Fig. 7 Time-averaged translational velocities of the spherocylindrical particles and spherical particles during $5-10 \mathrm{~s}$ at a $U_{\mathrm{g}}=1.6 \mathrm{~m} / \mathrm{s}$ and $\mathbf{b}$ $U_{\mathrm{g}}=2.0 \mathrm{~m} / \mathrm{s}$

of the two particles become very close. The time required for particle mixing can be roughly estimated by the moment when the average velocities of the two particles become very close. Particles mix faster when the superficial gas velocity is $2.0 \mathrm{~m} / \mathrm{s}$, compared with the superficial gas velocity of $1.6 \mathrm{~m} / \mathrm{s}$.

Moreover, Fig. 7 shows time-averaged translational velocities of the spherocylindrical particles and spherical particles during 5-10 s. It can be clearly seen that as the superficial gas velocity increases, time-averaged translational particle velocities in the bed increase. In addition, as the volume fraction of the spherocylindrical particles increases, time-averaged translational particle velocities in the bed also increase. This might be explained that nonspherical particles have larger drag at the same superficial gas velocity. 

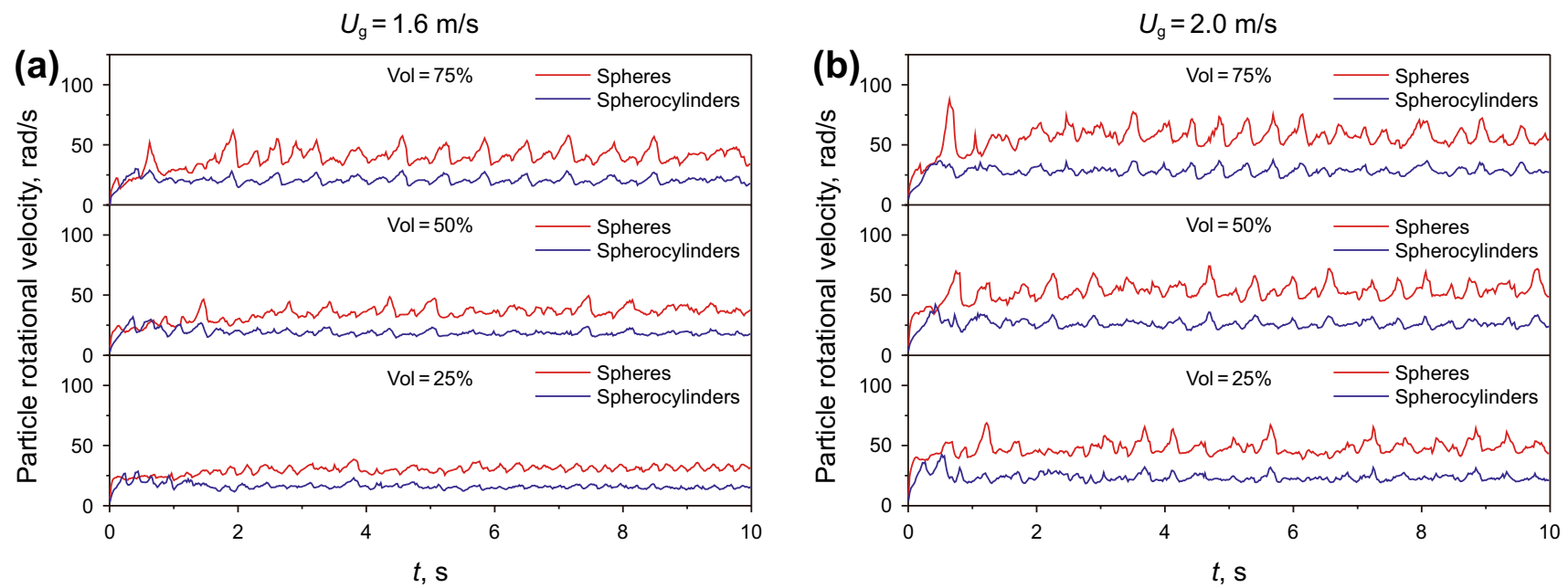

Fig. 8 The average rotational velocities of the spherocylindrical particles and spherical particles. a $U_{\mathrm{g}}=1.6 \mathrm{~m} / \mathrm{s}, \mathbf{b} U_{\mathrm{g}}=2.0 \mathrm{~m} / \mathrm{s}$
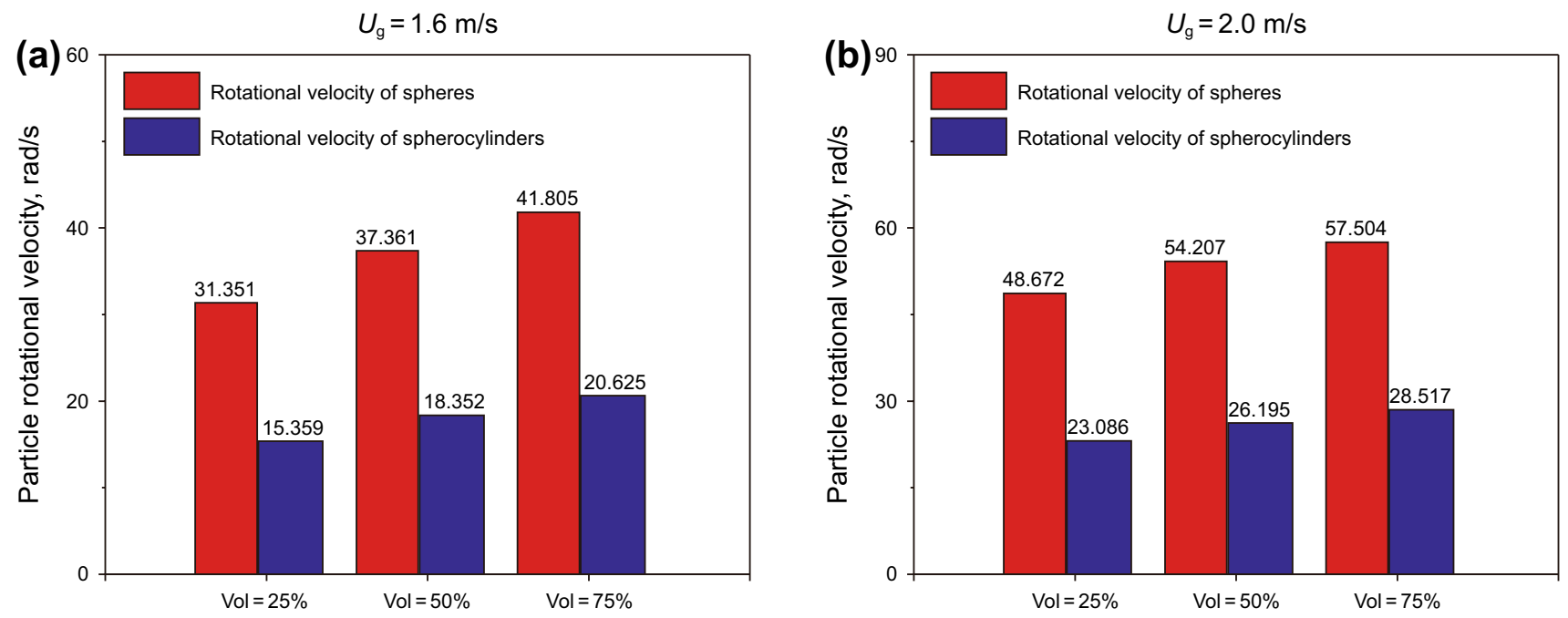

Fig. 9 Time-averaged rotational velocities of the spherocylindrical particles and spherical particles during $5-10 \mathrm{~s}$ at $\mathbf{a} U_{\mathrm{g}}=1.6 \mathrm{~m} / \mathrm{s}$ and $\mathbf{b}$ $U_{\mathrm{g}}=2.0 \mathrm{~m} / \mathrm{s}$

The averaged rotational velocities of the spherocylindrical particles and spherical particles during 0-10 $\mathrm{s}$ are shown in Fig. 8. The average particle rotational velocities are calculated by:

$\left|\omega_{\mathrm{p}}\right|=\frac{1}{N} \sum_{i=1}^{N} \sqrt{\omega_{\mathrm{p} x}^{2}+\omega_{\mathrm{p} y}^{2}+\omega_{\mathrm{p} z}^{2}}$
It can be observed that even if the particles are uniformly mixed, the average rotational velocities of the spherical particles are larger than that of the spherocylindrical particles. This may be due to the fact that the spherocylindrical particles are in contact with more particles and the rotational resistance is larger.

In addition, Fig. 9 shows time-averaged rotational velocities of the spherocylindrical particles and spherical particles during 

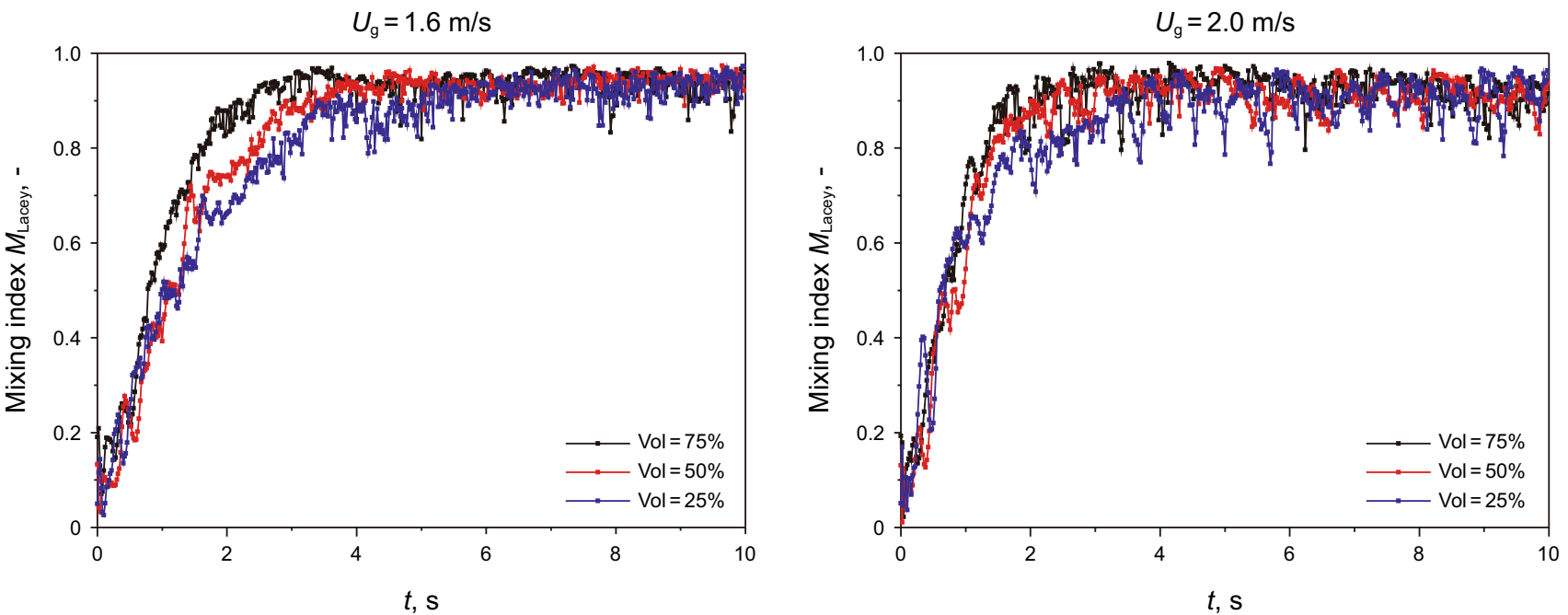

Fig. 10 Variation of Lacey mixing index with time at $U_{\mathrm{g}}=1.6 \mathrm{~m} / \mathrm{s}$ and $U_{\mathrm{g}}=2.0 \mathrm{~m} / \mathrm{s}$

(a)

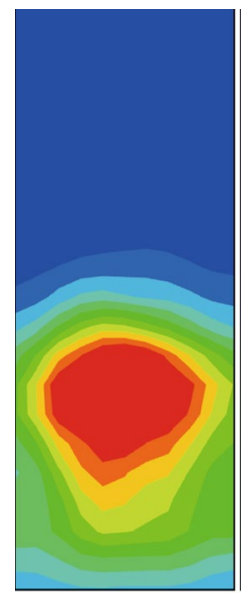

$\mathrm{Vol}=75 \%$
Spherocylindrical particles

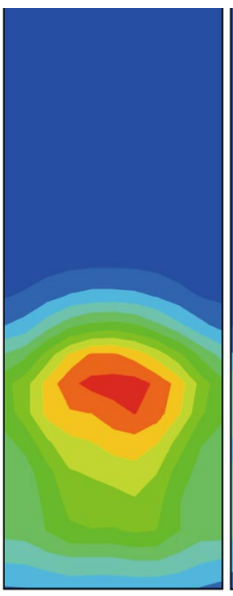

$\mathrm{Vol}=50 \%$

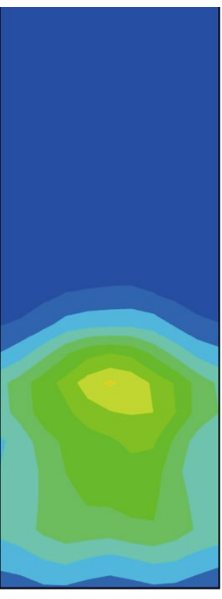

$\mathrm{Vol}=25 \%$ (b)

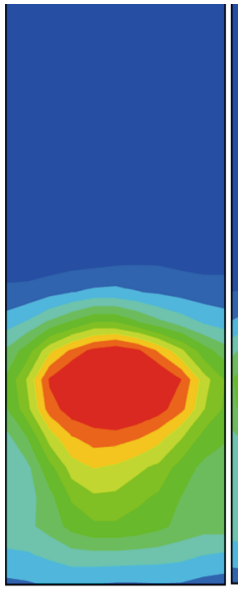

$\mathrm{Vol}=75 \%$

Spherical particles

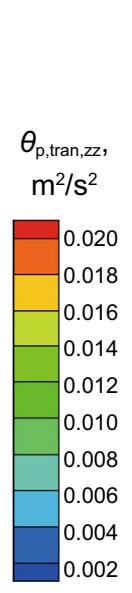

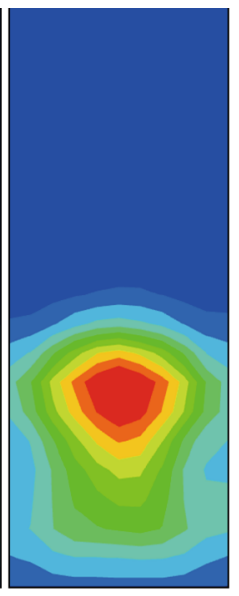

$\mathrm{Vol}=25 \%$

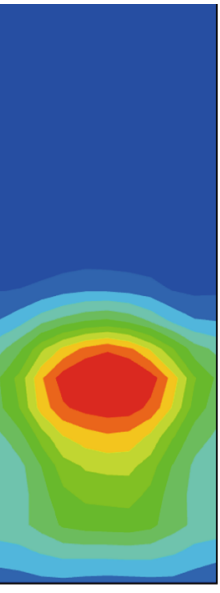

$\mathrm{Vol}=50 \%$ $\theta_{\mathrm{p}, \operatorname{tran}, \mathrm{zz}}$, $\mathrm{m}^{2} / \mathrm{s}^{2}$

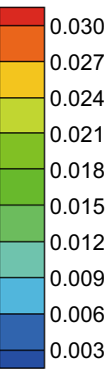

0.003

Fig. 11 Translational granular temperature distribution in $z$ direction $\left(U_{\mathrm{g}}=2.0 \mathrm{~m} / \mathrm{s}\right)$. a Spherocylindrical particles $(\mathrm{Vol}=75 \%$, Vol $=50 \%$, $\mathrm{Vol}=25 \%)$, b spherical particles $(\mathrm{Vol}=75 \%, \mathrm{Vol}=50 \%, \mathrm{Vol}=25 \%)$

5-10 s. The results indicate that time-averaged rotational particle velocities in the bed increase with the increase in superficial gas velocity. As the volume fraction of the spherocylindrical particles increases, time-averaged rotational particle velocities in the bed also increase slightly.

To further analyze the particle mixing process, the Lacey mixing index (Lacey 1954) was used to quantitatively describe the mixing of binary particles:
$M_{\text {Lacey }}=\frac{\sigma_{0}^{2}-\sigma^{2}}{\sigma_{0}^{2}-\sigma_{r}^{2}}$

The variance defined as the square of the standard deviation can be calculated by the following formula: 
$\sigma^{2}=\frac{1}{N-1} \sum_{i=1}^{N}\left(c_{i}-\bar{c}\right)^{2}$

where $N$ is the number of subcells; $c_{i}$ is the local concentration of sample particles; $\bar{c}$ is the average concentration of sample particles; and $\sigma_{0}^{2}$ and $\sigma_{r}^{2}$ are the variances of the fully separated state and the completely mixed state, respectively.

The Lacey mixing index is 0 for the fully separated state, and the Lacey mixing index is 1 for the completely mixed state. The spherocylindrical particles are equally divided into equal volumes of spherical elements, and then, the Lacey mixing index is calculated using spherical elements and spherical particles. Figure 10 shows the Lacey mixing index during $0-10 \mathrm{~s}$ at the superficial gas velocity of $1.6 \mathrm{~m} / \mathrm{s}$ and $2.0 \mathrm{~m} / \mathrm{s}$. It can be seen that the mixing index of both superficial gas velocities can reach a value close to 1 , which indicates that the spherocylindrical particles and the spherical particles can achieve good mixing. However, corresponding mixing index can reach the stability more quickly when the superficial gas velocity is $2.0 \mathrm{~m} / \mathrm{s}$, which demonstrates that increasing the superficial gas velocity can accelerate the mixing of the particles. Moreover, when the superficial gas velocity is the same, as the volume fraction of the spherocylindrical particles increases, the particle mixing is slightly accelerated.

(a)

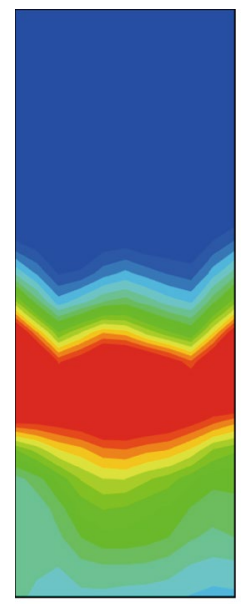

Spherocylindrical particles
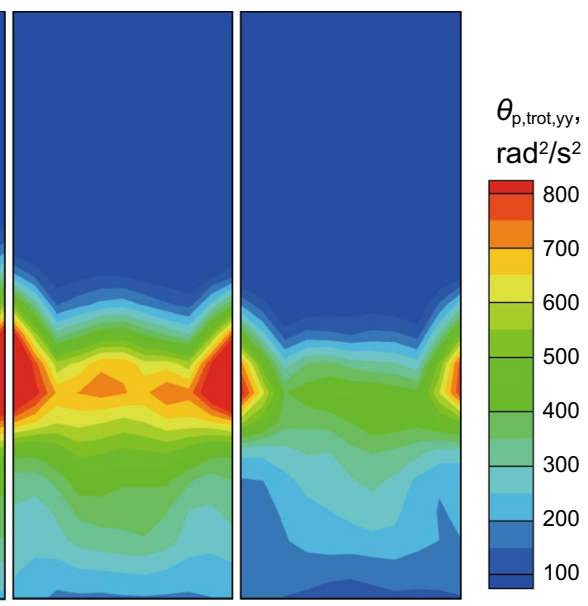

Vol $=75 \%$

$\mathrm{Vol}=50 \%$

$\mathrm{Vol}=25 \%$ (b)

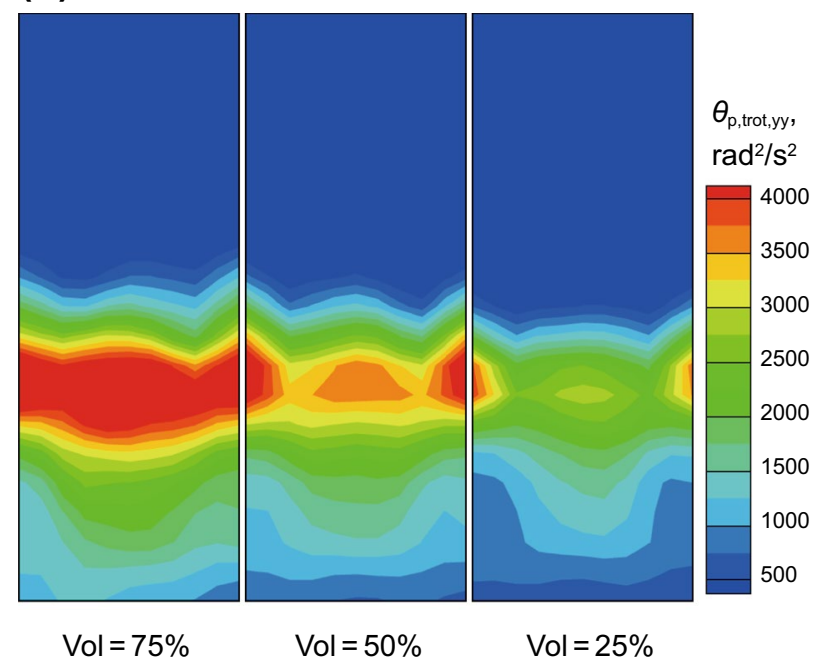

Fig. 12 Rotational granular temperature distribution in $y$ direction $\left(U_{\mathrm{g}}=2.0 \mathrm{~m} / \mathrm{s}\right)$, a spherocylindrical particles $($ Vol $=75 \%$, Vol $=50 \%$, $\mathrm{Vol}=25 \%)$, b spherical particles $(\mathrm{Vol}=75 \%, \mathrm{Vol}=50 \%, \mathrm{Vol}=25 \%)$ 
fraction of the spherocylindrical particles increases, the rotational granular temperature of the particles gradually increases.

\subsection{Particle orientation distribution}

The orientation of the spherocylindrical particles significantly affects the fluidization and mixing of particles. In this paper, the orientation angle was defined on the $\mathrm{X}-\mathrm{O}-\mathrm{Z}$ plane and varied from $0^{\circ}$ to $90^{\circ}$ for quantification, similar to the definition of Zhou et al. (2011). $0^{\circ}$ corresponds to the particles in horizontal direction (the long axis of the particle is parallel to the $x$-axis), and $90^{\circ}$ represents the particles in vertical direction (the long axis of the particle is parallel to the $z$-axis). A schematic view of the orientation angle of spherocylindrical particles is shown in Fig. 13a. The orientation angle is divided into six ranges with an interval of $15^{\circ}$ (i.e., $0^{\circ}-15^{\circ}, 15^{\circ}-30^{\circ}, 30^{\circ}-45^{\circ}, 45^{\circ}-60^{\circ}, 60^{\circ}-75^{\circ}$, $75^{\circ}-90^{\circ}$ ), and particles are counted at every angle range to calculate the percentage distribution of particle orientation.

Figure 13 shows the percentage distribution of particle orientation for $\mathrm{Vol}=100 \%$ during $0-10 \mathrm{~s}$ at the superficial gas velocity of $1.6 \mathrm{~m} / \mathrm{s}$ and $2.0 \mathrm{~m} / \mathrm{s}$. It can be seen that the spherocylindrical particles tend to be horizontally oriented at the initial packing state. When entering the fluidization stage, the tendency of the horizontal orientation of the spherocylindrical particles is weakened, and the tendency of the vertical orientation is increased. Moreover, the results indicate that as the superficial gas velocity increases, the tendency of the horizontal orientation of the rod-shaped particles decreases, and the particles tend to be more vertically oriented.

Figure 14 shows the percentage distribution of the orientation of the spherocylindrical particles at the superficial gas velocity of $2.0 \mathrm{~m} / \mathrm{s}$. It can be found that as the volume fraction of the spherocylindrical particles decreases, the percentage of the vertical orientation increases, that is, the addition of the spherical particles makes the spherocylindrical particles preferably distributed in a vertical orientation. There are two possible reasons for the vertical orientation of the spherocylindrical particles in a fluidized bed. On the one hand, it is related to the action of the drag force. When the spherocylindrical particles are horizontally oriented, the cross-sectional area in the vertical flow direction is large, resulting in a large drag force, which causes the particles to move in a direction in which the flow resistance is reduced. On the other hand, the addition of spherical particles increases the voids in the fluidized bed. The increase in the movement space of the spherocylindrical particles helps to reduce the interlocking phenomenon and promote (a) Schematic of the orientation angle of the spherocylindrical particles
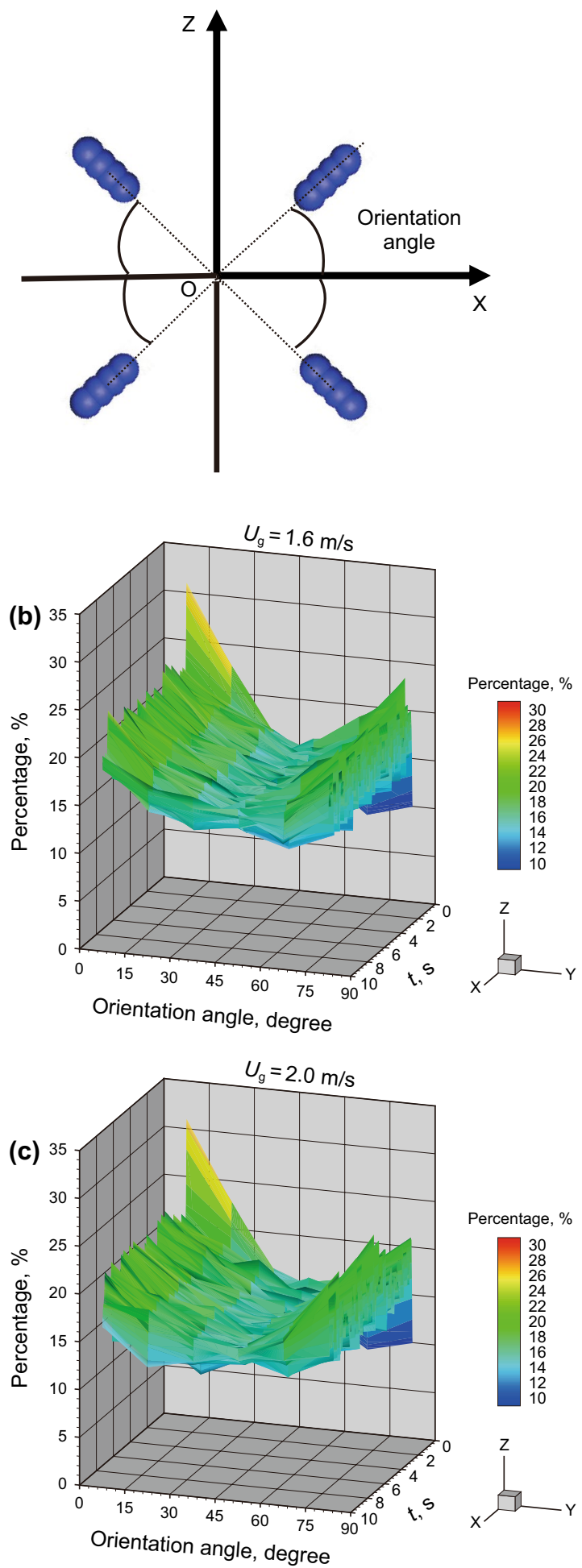

Fig. 13 Particle orientation distribution at $U_{\mathrm{g}}=1.6 \mathrm{~m} / \mathrm{s}$ and $U_{\mathrm{g}}=2.0 \mathrm{~m} / \mathrm{s}(\mathrm{Vol}=100 \%)$, a schematic of the orientation angle of the spherocylindrical particles, b $U_{\mathrm{g}}=1.6 \mathrm{~m} / \mathrm{s}, \mathbf{c} U_{\mathrm{g}}=2.0 \mathrm{~m} / \mathrm{s}$ 

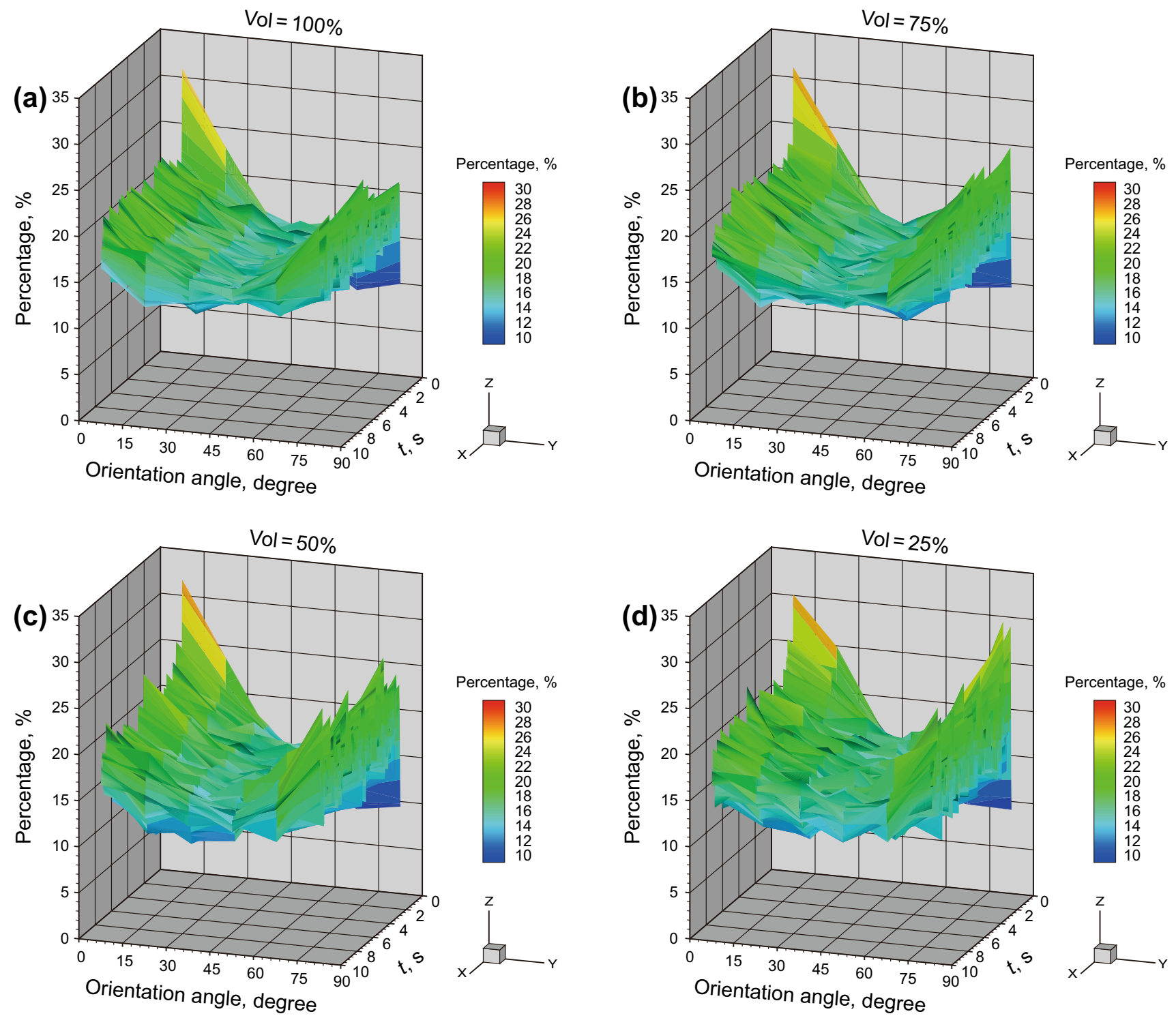

Fig. 14 Particle orientation distribution $\left(U_{\mathrm{g}}=2.0 \mathrm{~m} / \mathrm{s}\right), \mathbf{a} \mathrm{Vol}=100 \%, \mathbf{b} \mathrm{Vol}=75 \%, \mathbf{c} \mathrm{Vol}=50 \%$, d Vol $=25 \%$

the fluidization of the spherocylindrical particles. In conclusion, the combined effect of the two aspects makes the spherocylindrical particles in the binary granular system preferably oriented vertically.

In order to investigate the orientation distribution of the binary mixture in the vicinity of the walls, the time-average orientation of the spherocylindrical particles in each $10-\mathrm{mm}$ region near the left- and right-side walls (marked in blue) is counted as shown in Fig. 15. It can be seen that the particles in the vicinity of the side walls are more vertically oriented due to the wall effect. The superficial gas velocity increases, and the vertical orientation trend is still obvious, indicating that the wall effect dominates the orientation behavior of the spherocylindrical particles in the vicinity of the walls. 

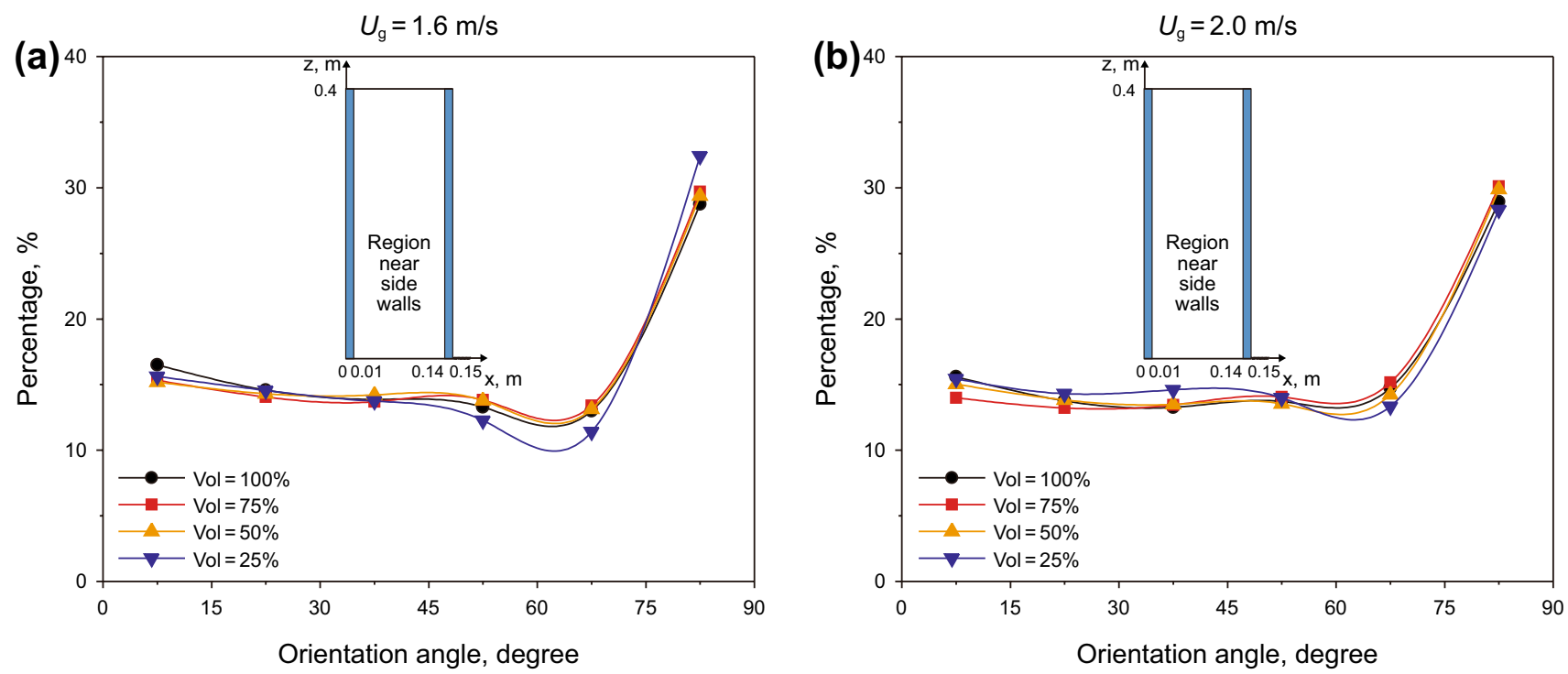

Fig. 15 Particle orientation distribution in the vicinity of the left and right walls, a $U_{\mathrm{g}}=1.6 \mathrm{~m} / \mathrm{s}, \mathbf{b} U_{\mathrm{g}}=2.0 \mathrm{~m} / \mathrm{s}$

\section{Conclusion}

In this study, CFD-DEM approach with rolling resistance was applied to evaluate the mixing behaviors of binary mixtures comprising spherocylindrical particles and spherical particles in a fluidized bed. The effects of the volume fraction of the spherocylindrical particles on the macroscopic mixing characteristics and microscopic flow behaviors including granular temperature and orientation distribution were discussed.

Increasing the superficial gas velocity accelerates the mixing process of the particles. Furthermore, when the superficial gas velocity is the same, as the volume fraction of the spherocylindrical particles increases, the particle mixing is slightly accelerated. Moreover, when well mixed, the average translational velocities of the spherocylindrical and spherical particles become very close, but the average rotational velocities of the spherical particles are larger.

In the fluidized bed, the translational granular temperature of the spherical particles is slightly larger than that of the spherocylindrical particles and the rotational granular temperature of the spherical particles is much larger than that of the spherocylindrical particles. Moreover, as the volume fraction of the spherocylindrical particles increases, the translational and rotational granular temperatures of the particles gradually increase.

In the binary granular system, as the volume fraction of the spherocylindrical particles decreases, the percentage of the vertical orientation increases, that is, the addition of the spherical particles makes the spherocylindrical particles preferably distributed in a vertical orientation. In addition, the wall effect dominates the orientation behavior of the spherocylindrical particles in the vicinity of the walls.

Acknowledgements This work is financially supported by the National Natural Science Foundation of China (Grant No. 51706055).

Open Access This article is distributed under the terms of the Creative Commons Attribution 4.0 International License (http://creativeco mmons.org/licenses/by/4.0/), which permits unrestricted use, distribution, and reproduction in any medium, provided you give appropriate credit to the original author(s) and the source, provide a link to the Creative Commons license, and indicate if changes were made.

\section{References}

Boer L, Buist KA, Deen NG, Padding JT, Kuipers JAM. Experimental study on orientation and de-mixing phenomena of elongated particles in gas-fluidized beds. Powder Technol. 2018;329:332-44. https://doi.org/10.1016/j.powtec.2018.01.083.

Brilliantov NV, Pöschel T. Rolling friction of a viscous sphere on a hard plane. Europhys Lett. 1998;42(5):511.

Cai J, Li Q, Yuan Z. Orientation of cylindrical particles in gas-solid circulating fluidized bed. Particuology. 2012;10(1):89-96. https ://doi.org/10.1016/j.partic.2011.03.012.

Chen J, Lu X. Progress of petroleum coke combusting in circulating fluidized bed boilers - a review and future perspectives. Resour Conserv Recycl. 2007;49(3):203-16. https://doi.org/10.1016/j. resconrec.2006.03.012.

Cui H, Grace JR. Fluidization of biomass particles: a review of experimental multiphase flow aspects. Chem Eng Sci. 2007;62(1-2):4555. https://doi.org/10.1016/j.ces.2006.08.006.

Cundall PA, Strack ODL. A discrete numerical model for granular assemblies. Geotechnique. 1979;29(1):47-65.

Di Felice R. The voidage function for fluid-particle interaction systems. Int J Multiph Flow. 1994;20(1):153-9. https://doi. org/10.1016/0301-9322(94)90011-6. 
Favier JF, Abbaspour-Fard MH, Kremmer M, Raji AO. Shape representation of axi-symmetrical, non-spherical particles in discrete element simulation using multi-element model particles. Eng Comput. 1999;16(4):467-80. https://doi.org/10.1108/0264440991 0271894

Fotovat F, Chaouki J, Bergthorson J. The effect of biomass particles on the gas distribution and dilute phase characteristics of sand-biomass mixtures fluidized in the bubbling regime. Chem Eng Sci. 2013;102:129-38. https://doi.org/10.1016/j. ces.2013.07.042.

Fotovat F, Chaouki J, Bergthorson J. Distribution of large biomass particles in a sand-biomass fluidized bed: experiments and modeling. AIChE J. 2014;60(3):869-80. https://doi.org/10.1002/ aic.14337.

Gan JQ, Zhou ZY, Yu AB. Micromechanical analysis of flow behaviour of fine ellipsoids in gas fluidization. Chem Eng Sci. 2017;163:11-26. https://doi.org/10.1016/j.ces.2017.01.020.

Ganser GH. A rational approach to drag prediction of spherical and nonspherical particles. Powder Technol. 1993;77(2):143-52. https://doi.org/10.1016/0032-5910(93)80051-B.

Goniva C, Kloss C, Deen NG, Kuipers JAM, Pirker S. Influence of rolling friction on single spout fluidized bed simulation. Particuology. 2012;10(5):582-91. https://doi.org/10.1016/j.partic.2012.05.002.

He Y, Peng W, Tang T, Yan S, Zhao Y. DEM numerical simulation of wet cohesive particles in a spout fluid bed. Adv Powder Technol. 2016;27(1):93-104. https://doi.org/10.1016/j.apt.2015.10.022.

Hilton JE, Mason LR, Cleary PW. Dynamics of gas-solid fluidised beds with non-spherical particle geometry. Chem Eng Sci. 2010;65(5):1584-96. https://doi.org/10.1016/j.ces.2009.10.028.

Hölzer A, Sommerfeld M. New simple correlation formula for the drag coefficient of non-spherical particles. Powder Technol. 2008;184(3):361-5. https://doi.org/10.1016/j.powte c.2007.08.021.

Jung J, Gidaspow D, Gamwo IK. Measurement of two kinds of granular temperatures, stresses, and dispersion in bubbling beds. Ind Eng Chem Res. 2005;44(5):1329-41. https://doi.org/10.1021/ie049 6838.

Kruggel-Emden H, Stepanek F, Munjiza A. A study on adjusted contact force laws for accelerated large scale discrete element simulations. Particuology. 2010;8(2):161-75. https://doi.org/10.1016/j. partic.2009.07.006.

Lacey PMC. Developments in the theory of particle mixing. J Appl Chem. 1954;4(5):257-68. https://doi.org/10.1002/jctb.50100 40504.

Leith D. Drag on nonspherical objects. Aerosol Sci Technol. 1987;6(2):153-61. https://doi.org/10.1080/027868287089591 28.

Liu D, van Wachem B. Comprehensive assessment of the accuracy of CFD-DEM simulations of bubbling fluidized beds. Powder Technol. 2019;343:145-58. https://doi.org/10.1016/j.powte c.2018.11.025.

Luo K, Wu F, Yang S, Fan J. Numerical investigation of the time-related properties of solid phase in a 3-D spout-fluid bed. Chem Eng J. 2015;267:207-20. https://doi.org/10.1016/j.cej.2014.12.064.

Luo K, Yang S, Fang M, Fan J, Cen K. LES-DEM investigation of the solid transportation mechanism in a 3-D bubbling fluidized bed. Part I: hydrodynamics. Powder Technol. 2014;256:385-94. https://doi.org/10.1016/j.powtec.2013.11.039.

$\mathrm{Ma} \mathrm{H}, \mathrm{Xu}$ L, Zhao Y. CFD-DEM simulation of fluidization of rodlike particles in a fluidized bed. Powder Technol. 2017;314:35566. https://doi.org/10.1016/j.powtec.2016.12.008.
Ma H, Zhao Y. CFD-DEM investigation of the fluidization of binary mixtures containing rod-like particles and spherical particles in a fluidized bed. Powder Technol. 2018;336:533-45. https://doi. org/10.1016/j.powtec.2018.06.034.

Müller CR, Holland DJ, Sederman AJ, Scott SA, Dennis JS, Gladden LF. Granular temperature: comparison of magnetic resonance measurements with discrete element model simulations. Powder Technol. 2008;184(2):241-53. https://doi.org/10.1016/j.powte c. 2007.11.046.

Ren B, Zhong W, Jin B, Shao Y, Yuan Z. Numerical simulation on the mixing behavior of corn-shaped particles in a spouted bed. Powder Technol. 2013;234:58-66. https://doi.org/10.1016/j. powtec.2012.09.024.

Shao Y, Zhong W, Yu A. Mixing behavior of binary and multicomponent mixtures of particles in waste fluidized beds. Powder Technol. 2016;304:73-80. https://doi.org/10.1016/j.powte c.2016.06.054.

Takeuchi S, Wang S, Rhodes M. Discrete element simulation of a flat-bottomed spouted bed in the 3-D cylindrical coordinate system. Chem Eng Sci. 2004;59(17):3495-504. https://doi. org/10.1016/j.ces.2004.03.027.

Tang T, He Y, Tai T, Wen D. DEM numerical investigation of wet particle flow behaviors in multiple-spout fluidized beds. Chem Eng Sci. 2017;172:79-99. https://doi.org/10.1016/j.ces.2017.06.025.

Tartan M, Gidaspow D. Measurement of granular temperature and stresses in risers. AIChE J. 2004;50(8):1760-75. https://doi. org/10.1002/aic.10192.

Tran-Cong S, Gay M, Michaelides EE. Drag coefficients of irregularly shaped particles. Powder Technol. 2004;139(1):21-32. https://doi. org/10.1016/j.powtec.2003.10.002.

Tsuji Y, Kawaguchi T, Tanaka T. Discrete particle simulation of twodimensional fluidized bed. Powder Technol. 1993;77(1):79-87. https://doi.org/10.1016/0032-5910(93)85010-7.

Van Buijtenen MS, Van Dijk WJ, Deen NG, Kuipers JAM, Leadbeater T, Parker DJ. Numerical and experimental study on multiple-spout fluidized beds. Chem Eng Sci. 2011;66(11):2368-76. https://doi. org/10.1016/j.ces.2011.02.055.

Van Der Hoef MA, Ye M, van Sint AM, Andrews AT IV, Sundaresan S, Kuipers JAM. Multiscale modeling of gas-fluidized beds. Adv Chem Eng. 2006;31:65-149. https://doi.org/10.1016/S0065 -2377(06)31002-2.

Vollmari K, Oschmann T, Wirtz S, Kruggel-Emden H. Pressure drop investigations in packings of arbitrary shaped particles. Powder Technol. 2015;271:109-24. https://doi.org/10.1016/j.powte c.2014.11.001.

Wachem BV, Zastawny M, Zhao F, Mallouppas G. Modelling of gassolid turbulent channel flow with non-spherical particles with large Stokes numbers. Int J Multiph Flow. 2015;68:80-92. https ://doi.org/10.1016/j.ijmultiphaseflow.2014.10.006.

Wang T, He Y, Kim DR. Granular temperature and rotational characteristic analysis of a gas-solid bubbling fluidized bed under different gravities using discrete hard sphere model. Powder Technol. 2015;271:35-48. https://doi.org/10.1016/j.powtec.2014.11.005.

Wang T, He Y, Tang T, Peng W. Experimental and numerical study on a bubbling fluidized bed with wet particles. AIChE J. 2016a;62(6):1970-85. https://doi.org/10.1002/aic.15195.

Wang T, He Y, Tang T, Zhao Y. Numerical investigation on particle behavior in a bubbling fluidized bed with non-spherical particles using discrete hard sphere method. Powder Technol. 2016b;301:927-39. https://doi.org/10.1016/j.powtec.2016.07.005. 
Wang T, Tang T, He Y, Yi H. Analysis of particle behaviors using a region-dependent method in a jetting fluidized bed. Chem Eng J. 2016c;283:127-40. https://doi.org/10.1016/j.cej.2015.07.038.

Zhang Y, Jin B, Zhong W. Experimental investigation on mixing and segregation behavior of biomass particle in fluidized bed. Chem Eng Process Process Intensif. 2009;48(3):745-54. https://doi. org/10.1016/j.cep.2008.09.004.
Zhou ZY, Pinson D, Zou RP, Yu AB. Discrete particle simulation of gas fluidization of ellipsoidal particles. Chem Eng Sci. 2011;66(23):6128-45. https://doi.org/10.1016/j.ces.2011.08.041.

Zhou YC, Wright BD, Yang RY, Xun BH, Yu AB. Rolling friction in the dynamic simulation of sandpile formation. Physica A Stat Mech Appl. 1999;269(2-4):536-53. https://doi.org/10.1016/ S0378-4371(99)00183-1. 